\title{
Effect of tropical climate to compressive strength of high performance fibre reinforced concrete
}

\begin{abstract}
High performance fibre reinforced concrete (HPFRC) is relatively an advance fibre reinforced concrete (FRC) material, which is made of more than $2 \%$ volume fraction of fibres. This research focuses on the effect of tropical climate on the compressive strength of HPFRC. Total of 56 HPFRC cubes made of 3\%, 4\% and $5 \%$ of hooked-end fibres and grade 80 slurry were prepared. Half of which were exposed to tropical climate condition $(80 \%$ humidity at $35^{\circ} \mathrm{C}$ ) for 30 days which the other half are placed in room temperature. After which, the compression test was carried out. The highest compressive strength of $152.2 \mathrm{MPa}$ was recorded from samples made of $5 \%$ fibre volume and being exposed to tropical climate, which is $90 \%$ higher than the control sample.
\end{abstract}

Keyword: High performance fibre reinforced concrete; Water curing; Steam curing; Tropical climate 